\title{
Potret Kebijakan Pengendalian Demam Berdarah Dengue di Kabupaten Indramayu
}

\author{
Henri Peranginangin ${ }^{*}$ Hasim** Bambang Pramudya ${ }^{* * *}$ Sri Budiarti ${ }^{* * * * *}$
}

\begin{abstract}
Abstrak
Penyakit demam berdarah dengue (DBD) masih menjadi masalah di Kabupaten Indramayu. Penelitian ini bertujuan mengidentifikasi elemen-elemen prioritas kebijakan pengendalian penyakit DBD di Kabupaten Indramayu menurut pakar berdasarkan metode Analytical Hierarchy Process (AHP). Hasil penelitian menunjukkan "strategi utama" pengendalian penyakit DBD di Kabupaten Indramayu adalah peningkatan kesehatan lingkungan permukiman; "aktor utama pengendalian" ialah Pemerintah Kabupaten Indramayu; "faktor utama pengendalian" adalah lingkungan; "tujuan utama pengendalian" ialah Kabupaten Indramayu bebas penyakit DBD; dan "kriteria utama pengendalian" adalah jumlah dan mutu sumber daya manusia. Agar implementasi strategi pengendalian itu efektif maka Pemerintah Kabupaten Indramayu perlu meningkatkan kerja sama lintas program dan sektoral; dukungan teknologi, dana dan sarana pendidikan kesehatan lingkungan; mutu layanan Puskesmas; dan pengembangan tim pengendalian penyakit DBD dari tingkat Kabupaten sampai Desa/Kelurahan.
\end{abstract}

Kata kunci : Pengendalian, DBD, AHP, kesehatan, lingkungan.

\section{Abstract}

Dengue haemorrhagic fever (DHF) still becomes health problem in Indramayu district. The objective of this research is to identify the priority elements of DHF controlling policy in Indramayu district according to 35 experts using analytical hierarchy process (AHP). The result of the research provides information that the "main strategy" of DHF controlling is the improvement of healthy living environment; the "main actor" is the Government of Indramayu district; the "main factor" is the environment; the "main objective" is zero DHF in Indramayu district; and the "main criteria" is the quantity and quality of human resources. Based on this data, in order to implement the main strategy effectively, the Government of Indramayu district should increase the inter-program and inter-institutional cooperation; provide technological, funding, and facilities of environment health education supports; increase the quality of Puskesmas services and develop the DHF controlling team in all administrative level.

Key words : Controlling, DHF, AHP, health, environment.

*Fakultas Kedokteran Unversitas Al-Zaytun Indonesia, Ds.Mekar Jaya, Gantar Indramayu (Hp.081310774048)

**Laboratorium Biokimia Metabolik Fakultas MIPA Institut Pertanian Bogor, Jl. Raya Darmaga Kampus IPB Darmaga Bogor 16680

***Laboratorium Sistem dan Manajemen Mekanisasi Botani Fakultas Teknologi Pertanian Institut Pertanian Bogor, JI. Raya Darmaga Kampus IPB Darmaga Bogor 16680

****Laboratorium Mikrobiologi Departemen Biologi Fakultas MIPA Institut Pertanian Bogor, Jl. Raya Darmaga Kampus IPB Darmaga Bogor 16680 
Angka insiden DBD di Kabupaten Indramayu dalam periode tahun 2004-2008 berturut-turut: 49,74; 26,09; 35,92; 60,26; dan 50,01 per 100.000 penduduk. Angka tersebut relatif tinggi mendekati angka DBD nasional: 37,01; 52,10; 52,43; 71,78; dan 60,06. Sedangkan target angka insiden DBD nasional tahun 2010 adalah 2 per 100.000 penduduk. Case fatality rate (CFR) DBD dalam periode 2004-2008, berturut-turut 2,76; 3,41; 5,74; 5,15; dan 4,89 per 100 penderita, relatif lebih tinggi dari CFR DBD nasional berturut-turut 1,20; 1,36; 1,04; 1,01; dan 0,86.

Penyebab DBD diduga berhubunganan dengan faktor lingkungan, ${ }^{1-8}$ faktor kependudukan, ${ }^{1,9,10}$ faktor layanan kesehatan, ${ }^{1}$ faktor nyamuk penular (vektor) penyakit DBD,1,2 dan faktor mutu implementasi kebijakan. Obat penyakit DBD belum ditemukan, demikian pula vaksinnya; oleh sebab itu perbaikan kesehatan lingkungan melalui penyuluhan kepada masyarakat perlu dilaksanakan secara efektif dan kontinyu. ${ }^{1,11,12}$ Dampak positif pendidikan kesehatan bagi pengetahuan, sikap, dan perilaku masyarakat dalam pencegahan DBD adalah besar. ${ }^{13,14}$ Dalam rangka memperkaya bahan masukan dalam rangka analisis kebijakan pengendalian penyakit DBD di Kabupaten Indramayu penulis melakukan penelitian untuk mengidentifikasi elemen-elemen prioritas kebijakan pengendalian penyakit DBD menurut pakar.

\section{Metode}

Penelitian dilakukan pada bulan Mei sampai dengan
Oktober 2009 di Kabupaten Indramayu dengan metode pendekatan Analytical Hierarchy Process (AHP). ${ }^{15}$ Prinsip kerja AHP adalah penyederhanaan suatu persoalan kompleks yang tidak terstruktur, stratejik, dan dinamik menjadi bagian-bagiannya, serta menata dalam suatu hierarki. Kemudian, tingkat kepentingan setiap variabel diberi nilai numerik secara subjektif tentang arti penting variabel tersebut secara relatif dibandingkan dengan variabel yang lain. Dari berbagai pertimbangan tersebut, kemudian dilakukan sintesis untuk menetapkan variabel yang memiliki prioritas tinggi dan berperan untuk mempengaruhi hasil pada sistem tersebut. Adapun ide dasar prinsip kerja AHP yaitu penyusunan hierarki, penilaian kriteria dan alternatif, penentuan prioritas dan konsistensi logis. ${ }^{15}$

Data primer untuk keperluan AHP didasarkan pada elemen-elemen yang termasuk dalam struktur hierarki antar elemen pengendalian penyakit DBD di Kabupaten Indramayu, yaitu : level 1. Fokus yaitu Kebijakan pengendalian penyakit DBD di Kabupaten Indramayu; level 2. Aktor yaitu (1) Pemerintah Kabupaten Indramayu, (2) Pemerintah Kecamatan: Sindang, Indramayu, Jatibarang, Terisi, Sukagumiwang, dan Tukdana, (3)Pemerintah Desa/Kelurahan di Kecamatan Sindang, Indramayu, Jatibarang, Terisi, Sukagumiwang, Tukdana, dan (4) Lembaga Kemasyarakatan; level 3. Faktor yaitu lingkungan, kependudukan, layanan kesehatan, dan vektor penyakit; level 4. Tujuan yaitu (1) Kabupaten Indramayu bebas penyakit DBD, (2) meningkatnya kenyamanan/ke-

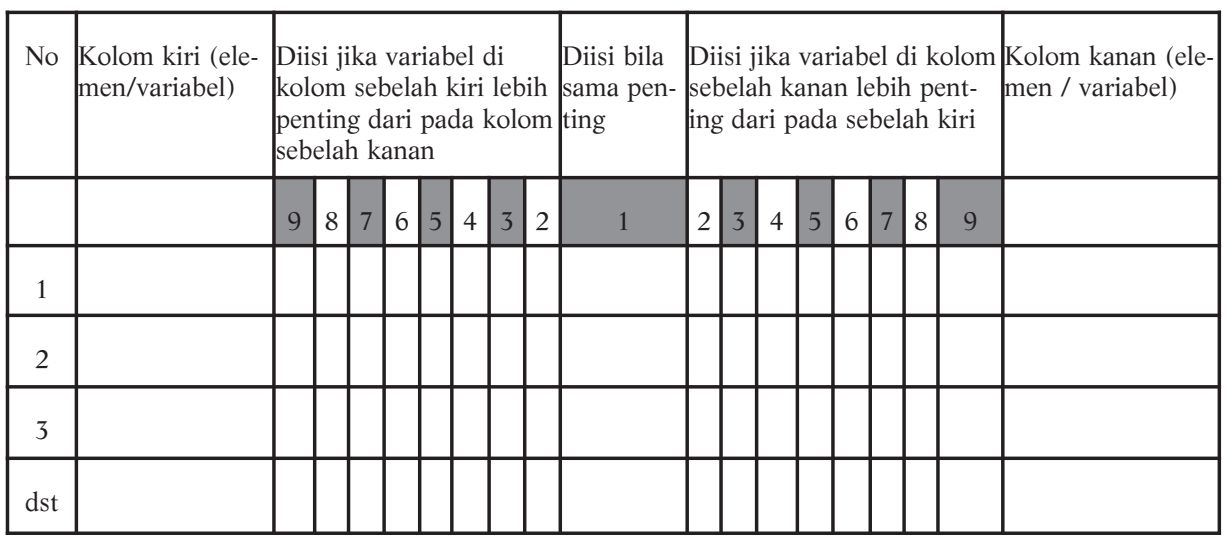

Gambar 1. Form Pengumpulan Data untuk Analitycal Hierarchy Process (AHP)

Keterangan Skor Penilaian :

\begin{tabular}{ll}
\hline Nilai Skor & Keterangan \\
\hline 1 & Elemen yang satu dengan elemen yang lainnya sama penting \\
3 & Elemen yang satu sedikit lebih penting (agak kuat) dibanding elemen yang lainnya \\
5 & Elemen yang satu lebih penting (lebih kuat pentingnya) dibanding elemen yang lainnya \\
7 & Elemen yang satu sangat penting dibanding elemen yang lainnya \\
9 & Elemen yang satu ekstrim pentingnya dibanding elemen yang lainnya \\
$2,4,6,8$ & Nilai tengah di antara dua nilai skor penilaian diatas \\
\hline
\end{tabular}


tenteraman masyarakat, dan (3) meningkatnya produktivitas kerja masyarakat; level 5. Kriteria yaitu (1) Teknologi, (2) Dana dan sarana, (3) Jumlah dan mutu sumber daya manusia, dan (4) Edukatif ; level 6. Strategi yaitu (1) Peningkatan kesehatan lingkungan permukiman, (2) Peningkatan kesiapan hidup sehat masyarakat, (3) Peningkatan layanan kesehatan kepada masyarakat, dan (4) Pengendalian vektor penyakit DBD.

Responden penelitian ini, diambil dengan teknik purposive sampling, yaitu pakar dari Departemen Kesehatan Republik Indonesia, Dinas Kesehatan Provinsi Jawa Barat, dan Dinas/Instansi/Perguruan Tinggi di Kabupaten Indramayu. Kepakaran ditetapkan menurut tingkat pendidikan, kompetensi dan pengalaman berkaitan pengendalian penyakit DBD. Data dikumpulkan dengan teknik wawancara dan pengisian questionnaire (contoh form seperti tampak pada Gambar 1) kemudian dianalisis dengan menggunakan Soft ware Expert Choice $2000 .{ }^{15}$

Hasil

Berdasarkan pengolahan dan analisis data diperoleh hasil bahwa berdasarkan "fokus" pengendalian penyakit
DBD di Kabupaten Indramayu, elemen terpenting pada level 2 (aktor) ialah Pemerintah Kabupaten Indramayu (nilai eigen 0,672), diikuti oleh Pemerintah kecamatan $(0,189)$, Pemerintah desa $(0,081)$, dan Lembaga kemasyarakatan $(0,058)$. Berdasarkan "aktor" pengendalian penyakit DBD di Kabupaten Indramayu, elemen terpenting pada level 3 (faktor) ialah lingkungan $(0,448)$, diikuti oleh kependudukan $(0,381)$, layanan kesehatan $(0,090)$, dan vektor penyakit $(0,082)$. Berdasarkan "faktor" pengendalian penyakit DBD di Kabupaten Indramayu, elemen terpenting pada level 4 (tujuan) ialah Kabupaten Indramayu bebas penyakit DBD $(0,693)$, diikuti oleh meningkatnya kenyamanan/ ketenteraman masyarakat $(0,162)$, dan meningkatnya produktivitas kerja masyarakat $(0,145)$. Berdasarkan "tujuan" pengendalian penyakit DBD di Kabupaten Indramayu, elemen terpenting pada level 5 (kriteria) ialah jumlah dan mutu sumber daya manusia $(0,340)$, diikuti oleh dana dan sarana $(0,309)$, edukatif $(0,274)$, dan teknologi $(0,077)$. Berdasarkan "kriteria"pengendalian penyakit DBD di Kabupaten Indramayu, elemen terpenting pada level 6 (strategi) ialah peningkatan kesehatan lingkungan permukiman $(0,546)$ diikuti oleh peningkatan kesiapan

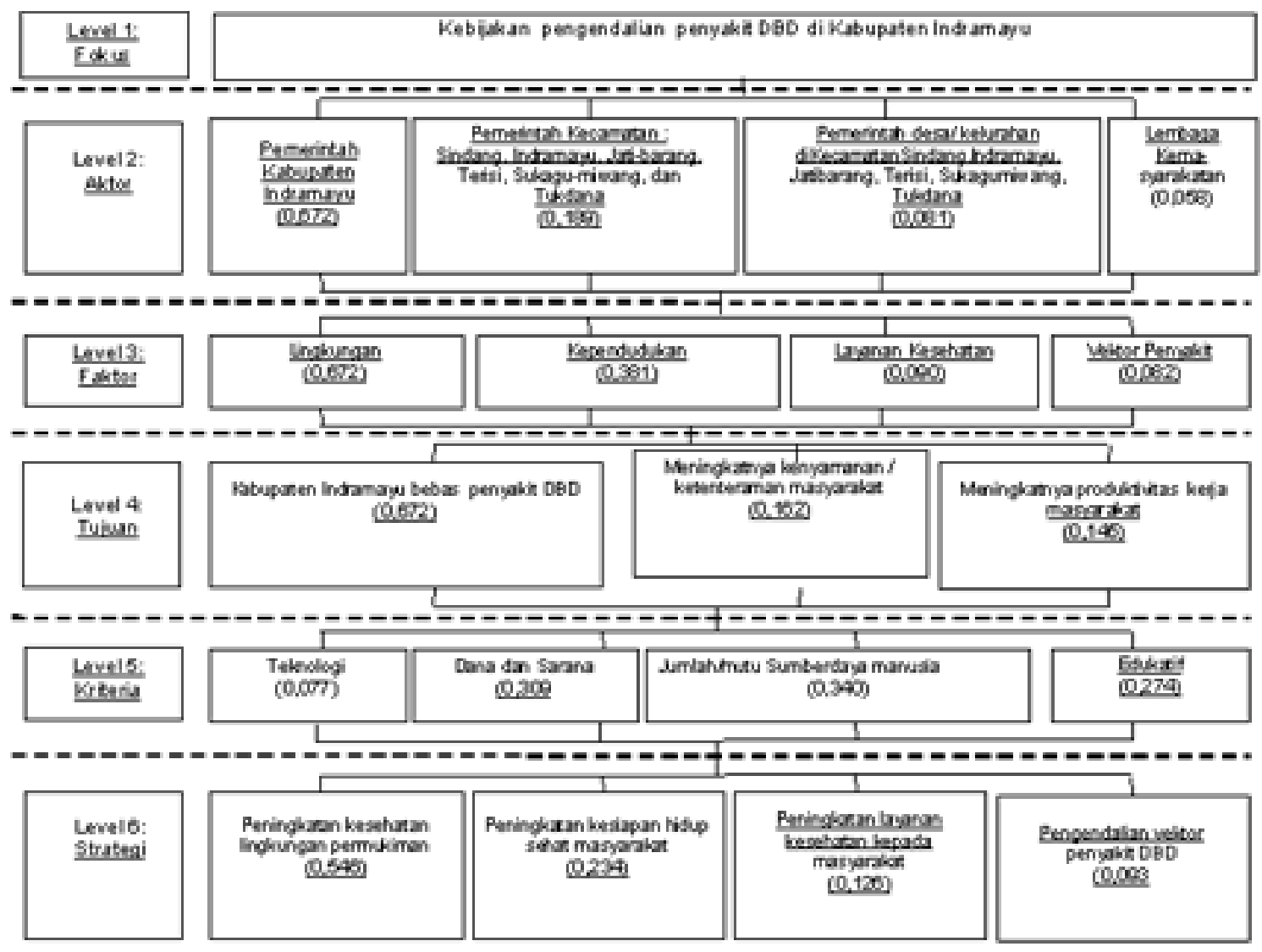

Gambar 2. Struktur Hierarki Antar Elemen Pengendalian Penyakit DBD di Kabupaten Indramayu 
hidup sehat masyarakat $(0,234)$, peningkatan layanan kesehatan kepada masyarakat $(0,126)$, dan pengendalian vektor penyakit DBD (0,093). Besar Consistency ratio (CR) setiap perbandingan berpasangan $<0,10$; artinya penilaian atau pembandingan berpasangan oleh seluruh responden telah dilakukan dengan konsekuen atau konsisten. ${ }^{15}$ Informasi mengenai keseluruhan elemen dengan nilai bobot masing-masing adalah seperti tampak pada Gambar 2.

\section{Pembahasan}

Menurut responden, elemen terpenting pada level “Aktor” ialah Pemerintah Kabupaten Indramayu. Pendapat ini pada umumnya didasarkan pada pemikiran bahwa desentralisasi bidang kesehatan yang luas dan utuh diletakkan di kabupaten. Daerah diberi kewenangan seluas-luasnya untuk menyelenggarakan upaya dan pelayanan kesehatan dengan standar pelayanan minimal. Pemerintah kabupaten bertanggungjawab mengelola sumberdaya kesehatan yang tersedia di wilayahnya secara optimal guna mewujudkan kinerja sistem kesehatan wilayah. Dengan kata lain Pemerintah Kabupaten Indramayu bertugas, berwenang, dan bertanggungjawab dalam menganalisis kebijakan pengendalian penyakit DBD.

Elemen terpenting pada level "Faktor" ialah lingkungan. Pendapat ini didasari pemikiran bahwa faktor lingkungan berpengaruh paling besar terhadap kesehatan individu atau masyarakat. ${ }^{18}$ Penyakit DBD adalah penyakit menular berbasis lingkungan; artinya timbul dan mewabah penyakit DBD pada prinsipnya dapat dicegah dengan metode perbaikan kesehatan lingkungan. 1,11,12 Secara empiris kondisi kesehatan lingkungan Kabupaten Indramayu pada umumnya belum sepenuhnya sesuai dengan yang diinginkan. Elemen terpenting pada level "Tujuan" ialah Kabupaten Indramayu bebas penyakit DBD. Tujuan ini didasarkan pada visi dan misi Pemerintah dan Dinas Kesehatan Kabupaten Indramayu; dan juga mengacu pada target IR DBD nasional pada tahun 2010 adalah 2 (dua). Elemen terpenting pada level "Kriteria" ialah jumlah dan mutu sumber daya manusia. Pendapat ini juga didasarkan pada visi dan misi Pemerintah dan Dinas Kesehatan Kabupaten Indramayu serta pemikiran bahwa masyarakat adalah subyek dan obyek pengendalian penyakit DBD. Keberhasilan pengendalian penyakit DBD sangat tergantung pada tersedianya sumber daya manusia di Puskesmas sesuai kebutuhan. Elemen terpenting pada level "Strategi" ialah peningkatan kesehatan lingkungan permukiman. Pendapat ini didasari pemikiran bahwa dengan terwujudnya lingkungan permukiman yang sehat akan berdampak positif terhadap pengurangan jumlah tempat perindukan nyamuk Aedes aegypti (TPN) hingga nol.

Berdasarkan hasil analisis pendapat pakar tersebut berikut ini dikembangkan pokok-pokok pikiran dalam rangka penetapan kebijakan pengendalian penyakit DBD di Kabupaten Indramayu yaitu: (1) pengendalian penyakit DBD merupakan bagian integral dari program pembangunan kesehatan di Kabupaten Indramayu; (2) pengendalian penyakit DBD diselenggarakan dalam kerangka desentralisasi untuk mewujudkan otonomi daerah bidang kesehatan; (3) pengendalian penyakit DBD perlu didukung dengan peningkatan perilaku hidup bersih dan sehat melalui penyuluhan kesehatan masyarakat yang bermutu tinggi; (4) pengendalian penyakit DBD harus berorientasi pada tujuan, bersifat holistik, dan efektif. Selanjutnya, dalam rangka implementasi kebijakan tersebut perlu dikembangkan langkah-langkah operasional mulai dari tingkat kabupaten sampai tingkat RW/RT, mencakup: (1) peningkatan kerja sama lintas program/sektoral, serta pengembangan/pembentukan Tim Koordinasi Pengendalian Penyakit DBD tingkat Kabupaten/Kecamatan/ Desa/Kelurahan; (2) perumusan pokok-pokok kegiatan serta uraian tugas masing-masing anggota tim; (3) pengembangan/pembentukan Tim Pelaksana Pengendalian Penyakit DBD Tingkat RT/RW serta perumusan pokok-pokok kegiatan tim dan uraian tugas masing-masing anggota; dan (4) monitoring, evaluasi, dan pengembangan program.

\section{Kesimpulan}

Hasil penelitian menunjukkan strategi utama pengendalian penyakit DBD di Kabupaten Indramayu ialah peningkatan kesehatan lingkungan permukiman dengan kriteria utama berkembangnya jumlah dan mutu sumber daya manusia sesuai kebutuhan sehingga mampu mewujudkan tujuan utama yaitu Kabupaten Indramayu bebas DBD. Aktor utama pengendalian ialah Pemerintah Kabupaten Indramayu yang berorientasi pada faktor utama pengendalian yaitu lingkungan.

\section{Saran}

Dalam rangka analisis kebijakan pengendalian penyakit DBD secara lebih efektif, Pemerintah Kabupaten Indramayu seyogyanya memanfaatkan dan mengembangkan hasil penelitian ini sesuai dengan situasi dan kondisi di daerah.

\section{Daftar Pustaka}

1. WHO. Pencegahan dan penanggulangan penyakit demam dengue dan demam berdarah dengue. Suroso,T., S.R. Hadinegoro., S.Wuryadi., G. Simanjuntak., A.I. Umar., P.D. Pitoyo., R. Kustiastuti., A.R.A. Izhar [Editor]. Terjemahan dari: Prevention Control of Dengue and Dengue Haemorrhagic Fever. Jakarta: Departemen Kesehatan Republik Indonesia; 2003.

2. Soedarmo SSP. Demam berdarah (Dengue) pada anak. Jakarta: Universitas Indonesia; 1988. 
3. Azwar A. Pengantar epidemiologi. Edisi Revisi. Jakarta: Binarupa Aksara; 1999.

4. Hasyimi M. Pengetahuan dan sikap penduduk terhadap nyamuk penyakit demam berdarah (DBD) di Kelurahan Ancol, Jakarta Utara tahun 1993. Media Penelitian dan Pengembangan Kesehatan Departemen Kesehatan Republik Indonesia. 1996; VI: 02.

5. Bohra A and Andrianasolo H. Application of GIS in modeling of dengue risk based on socio-cultural data: case of Jalor, Rajasthan, India. Paper presented at the $22^{\text {nd }}$ Asian Conference on Remote Sensing.5-9 Nopember 2001. Centre for Remote Imaging. Sensing and Processing (CRISP). Singapore: National University; 2001.

6. Mustafa AJ. Global environmental change dan masalah kesehatan lingkungan. Inovasi Online. 2005; 3: Xvii.

7. Sintorini MM. Dinamika penularan demam berdarah dengue (DBD) dalam kaitan dengan pola variabilitas iklim (studi kejadian DBD di DKI Jakarta). Jakarta: Jurnal Teknik Lingkungan Universitas Trisakti; 2006.

8. Sumantri A. Pencegahan berbasis lingkungan terhadap penyakit demam berdarah dengue [disertasi]. Bogor: Institut Pertanian Bogor; 2008.

9. Fathi, Keman S, Wahyuni CU. Peran faktor lingkungan dan perilaku terhadap penularan demam berdarah dengue di Kota Mataram. Jurnal Kesehatan Lingkungan. 2005; 2 (1).
10. Bhattacharya SS, Kant L, Shah VM. Surveillance strategy and research priorities of DF/DHF in India-a review. Indian Council of Medical Research (ICMR). Bulletin. 2008; Volume 38.

11. Chakravarti A and Kumaria R. Virology Journal, Department of Microbiology, Maulana Azad Medical College, Associated Lok Nayak Hospital, Bahadur Shah Zafar Marg New Delhi-110002, India: 2005.

12. Renganathan E, Parks W, Lloyd L, Nathan MB, Hosein E, Odugleh A, et al. Towards sustaining behavioural impact in dengue prevention and control. Dengue Bulletin. 2003; Volume 27.

13. Kyu HH, Thu M, Van der Putten M. Myanmar migrant woman caretakers on prevention of dengue fever: a study on knowledge, attitude and practices in tak province, Thailand. AU J.T.. Thailand: Faculty of Nursing Science, Assumption University Bangkok: 2005. 9(2): 99-105 (Oct. 2005)

14. Tram TT, Anh NTN, Hung NT, Lan NT, Cam LT, Houng NP, et al. Heegaard. The impact of health education on mother's knowledge, atitude and practice (KAP) of dengue haemorrhagic fever. Dengue Bulletin. 2003; 27.

15. Marimin. Teknik dan aplikasi pengambilan keputusan kriteria majemuk. Jakarta: Grasindo; 2005. 